\title{
Second-Order Derivative UV Spectrophotometric and RP-HPLC Methods for the Analysis of Vildagliptin and Application for Dissolution Study
}

\author{
Amanda T. Barden ${ }^{*}$, , Bruna L. Piccoli ${ }^{\mathrm{a}}$, Nadia M. Volpato ${ }^{\mathrm{a}}$, Martin Steppe ${ }^{\mathrm{a}}$ \\ ${ }^{a}$ Programa de Pós-Graduação em Ciências Farmacêuticas, Universidade Federal do Rio Grande do Sul, Av. Ipiranga, 2752, \\ Porto Alegre, RS, 90610-000, Brazil \\ *Corresponding author: amandatbarden@gmail.com
}

\begin{abstract}
This study describes two analytical methods, by second-order derivative UV spectrophotometric by HPLC, for determination of vildagliptin, a drug used for treatment of type 2 Diabetes Mellitus that belongs to a therapeutic class called inhibitors of dipeptidyl peptidase 4 . The methods were validated in accordance with ICH and USP requirements. Analyses by UV derivative method were performed at $220 \mathrm{~nm}$, which was the zero crossing point of excipient solutions. HPLC was optimized and the analysis was carried out using a Zorbax Eclipse Plus RP-C8 column $(150 \mathrm{~mm} \times 4.6 \mathrm{~mm}, 5 \mu \mathrm{m})$, detection at $207 \mathrm{~nm}$, and potassium phosphate buffer solution $\mathrm{pH} 7.0$ : acetonitrile $(85: 15, \mathrm{v} / \mathrm{v})$ as mobile phase. In dissolution test, the conditions used were $0.01 \mathrm{~mol} \mathrm{~L}^{-1}$ hydrochloric acid in $900 \mathrm{~mL}$ of dissolution medium, USP apparatus 2 (paddle) and $50 \mathrm{rpm}$ stirring speed. Both methods were successfully applied for analysis of dissolution samples from marketed vildagliptin tablets.
\end{abstract}

Keywords: Vildagliptin, Derivative UV Spectrophotometry, HPLC, Dissolution Method, Validation.

\section{Introduction}

Diabetes mellitus is a progressive disease characterized by deterioration of pancreatic islet cell function and increased insulin resistance (1). It is a disease of multiple etiologies that affects quality of life of affected individuals (2).

Inhibitors of dipeptidyl peptidase-4 (DPP4) represent a new class of antidiabetic agents for the treatment of type 2 diabetes, which improves glycemic control by preventing the degradation of intestinal peptides, also known as incretins. In order to improve glycemic control and slowing disease progression, pharmacological and nonpharmacological alternatives have been developed. In relation to pharmacological intervention, the treatment with DPP-4 inhibitors have been considered $(3,4)$.

Vildagliptin (VLG), (S)-1-[N-(3-hydroxy1-adamantyl) glycyl] pyrrolidine-2-carbonitrile (Figure 1), is a potent and selective dipeptidyl peptidase-4 (DPP-4) inhibitor that improves glycemic control in patients with type 2 diabetes mellitus by increasing $\alpha$ - and $\beta$-cell responsiveness to glucose. It was approved in Europe as a complementary therapy to metformin, sulfonylurea and thiazolidinone (5).

Drug dissolution testing is known as an integral part used by pharmaceutical industry to guide in product development and quality control routine in order to monitor drug release characteristics (6).

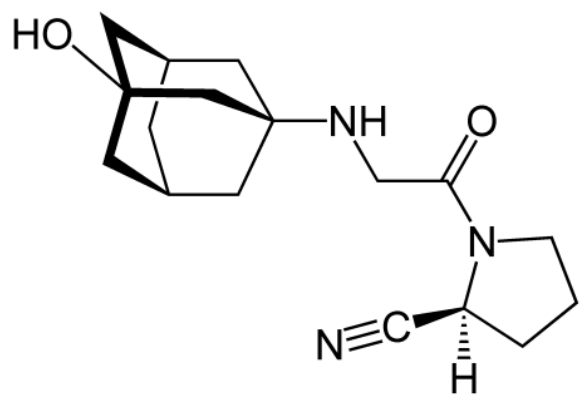

Figure 1. Chemical Structure of Vildagliptin.

As well as dissolution testing is essential to evaluate drug product performance, to assess batch-to-batch quality, to ensure continuing product quality and performance after certain changes, such as changes in the formulation or in the manufacturing process, the method validation is important and essential to ensure that the analytical method that will be used to analyze the dissolution media at different time points and quantify the amount of substance released is fit for its purpose $(7,8)$.

Once technological and scientific progress has led to the development of numerous synthetic drugs, it is imperative to develop analytical 
methods to determine these drugs in the quality control manufacturing phase of the pharmaceutical formulations. For this purpose, several analytical methods, including derivative spectrophotometry in the UV region have been used as a tool for quantitative analysis and quality control in pharmaceutical analysis. UV derivative spectrophotometry is an analytical technique of great utility for extracting both qualitative and quantitative information from overlapping bands of the analytes and interferences. The common availability of the instrumentation, the simplicity of procedures, speed, precision and accuracy of the technique still make spectrophotometric methods attractive (9-13).

In the literature, there were found some methods by using HPLC-UV for VLG quantitation in association with other drugs or alone (14-19) and by UV spectrophotometry based on chemical derivatization methods also for vildagliptin quantitation in pharmaceutical formulations (20,21). However, the chromatographic and spectrophotometric methods available were used for different purposes. Since there is no work related to evaluation of vildagliptin dissolution in tablets and no analytical methods were reported for this focus, the aim of this work was to develop and validate a discriminative dissolution method employing two analytical methods to determine vildagliptin by high-performance liquid chromatography (HPLC) and by second-order derivative UV spectrophotometry (2D-UV).

\section{Experimental}

\section{Material}

The reference standard for VLG (purity of 99.5\%) was purchased of Sequoia Researched Products (United Kingdom) and the commercial tablets containing $50 \mathrm{mg}$ of VLG (Galvus ${ }^{\circledR}$, Novartis Biociências S. A., SP, Brazil) were obtained from commercial sources within their shelf life period. The reference and sample solutions were filtered through a $0.45 \mu \mathrm{m}$ membrane filter (Millipore, Bedford, USA). Purified water was obtained by a Millipore ${ }^{\circledR}$ Direct-Q 3UV with pump (Molsheim, AL, France). All the other reagents were of analytical grade and buffer solutions were prepared according to USP 34 (22).

\section{D-UV Instrumentation}

UV-Vis UV-1800 double-beam spectrophotometer (Shimadzu, Kyoto, Japan) with $1 \mathrm{~cm}$ quartz cells was employed. UVProbe 2.33 software was used for instrument control and data acquisition. The second-order derivative spectra of solutions were recorded at a fast scan speed with a fixed slit to lead to a spectral resolution of $1 \mathrm{~nm}$. The spectra were obtained by instrumental electronic differentiation using a wavelength interval $(\Delta \lambda)$ of $8 \mathrm{~nm}$ in the range of $200-300 \mathrm{~nm}$. The determinations were made at $220 \mathrm{~nm}$. All analytical responses obtained were multiplied by 20 (scaling factor of 20). The spectrophotometric measurements were recorded by using water as a blank solution.

\section{HPLC Instrumentation}

Liquid chromatography (LC) method was carried out in a liquid chromatography (LC) Shimadzu 20-A system equipped with a CBM20A system controller, LC-20AT pump, SIL20A/C auto sampler, CTO-20A/C column oven and SPD-M2OA PDA detector. The experiments were performed on an analytical column Zorbax Eclipse Plus RP-C8 (150 mm x $4.6 \mathrm{~mm}, 5 \mu \mathrm{m})$. The LC system was operated isocratically at $25^{\circ} \mathrm{C}$ in the column oven, using a mobile-phase composed by a solution of $50 \mathrm{mM}$ potassium phosphate buffer and acetonitrile $(85: 15 \mathrm{v} / \mathrm{v})$, at a flow-rate of $1.0 \mathrm{ml} \mathrm{min}^{-1}$, using detection at 207 $\mathrm{nm}$. The $\mathrm{pH}$ of mobile phase was adjusted at 7.0 using phosphoric acid in the aqueous phase and, then, it was done the mixture of both aqueous and organic phases. The injection volume was $20 \mu \mathrm{L}$. The peak areas were integrated automatically by computer using LC-Solution manager system software.

\section{Dissolution performance}

Dissolution test was performed in a Vankel $^{\circledR} \quad$ VK 7010 multi-bath $(n=8)$, autosampling consisting of a bidirectional peristaltic pump. Vildagliptin $50 \mathrm{mg}$ tablets were dissolved in $900 \mathrm{~mL}$ of $0.01 \mathrm{~mol} \mathrm{~L}^{-1} \mathrm{HCl}$ at $37{ }^{\circ} \mathrm{C}$ using 
paddles. The collected samples were filtered through $0.45 \mu \mathrm{m}$ membrane filter.

\section{Solutions}

\section{Preparation of reference and sample solutions}

Stock solution was prepared by weighing accurately $25 \mathrm{mg}$ of VLG reference substance, transferred to individual $25 \mathrm{~mL}$ volumetric flask and diluted to volume with water, obtaining the concentration of $1.0 \mathrm{mg} \mathrm{mL}^{-1}$. The stock solution was stored at $2-8{ }^{\circ} \mathrm{C}$, protected from light and diluted to a final concentration of $50 \mu \mathrm{g} \mathrm{mL}^{-1}$ and $100 \mu \mathrm{g} \mathrm{mL}^{-1}$ (working solution) for HPLC and 2D-UV determinations, respectively.

The tablets containing $50 \mathrm{mg}$ of VLG were accurately weighed and crushed to fine powder. An appropriate amount was transferred into an individual $25 \mathrm{~mL}$ volumetric flask, diluted to volume with water, sonicated for $10 \mathrm{~min}$ and filtered through a filter paper, obtaining the concentration of $1.0 \mathrm{mg} \mathrm{mL}^{-1}$ of VLG. This stock solution was stored at $2-8{ }^{\circ} \mathrm{C}$ and protected from light. Working sample solutions were prepared by diluting the stock solution to appropriate concentrations (50 and $100 \mu \mathrm{g} \mathrm{mL}^{-1}$ for HPLC and $2 \mathrm{D}-\mathrm{UV}$, respectively) in purified water.

\section{Methods}

\section{HPLC and 2D-UV Method Validation}

The proposed methods were validated for drug specificity, linearity, precision, accuracy and robustness according with USP (22) and ICH (23) guidelines. Specificity was evaluated by interference of excipients from formulation. Linearity of three analytical curves were prepared with seven concentrations at ranges 25-175 $\mu \mathrm{g}$ $\mathrm{mL}^{-1}$ and $10-90 \mu \mathrm{g} \mathrm{mL}^{-1}$ of reference solution for 2D-UV and HPLC, respectively. The results obtained were plotted against the respective drug concentrations to obtain the analytical curve. The precision was performed through six sample solutions, at the concentrations of $100 \mu \mathrm{g} \mathrm{mL}^{-1}$ and $50 \mu \mathrm{g} \mathrm{mL} \mathrm{g}^{-1}$ to 2D-UV and HPLC, respectively. The relative standard deviation (RSD) was determined on three different days for intra-day and inter-day precisions. Accuracy was calculated in relation of the percentage of recovery by the assay of known added amount of vildagliptin reference solution using three concentration levels. The added levels were 25, 50 and $75 \%$ of the nominal drug concentration. Robustness was evaluated by Plackett-Burman experimental design in order to detect potential sources of variability in the analytical methods in an interval that slightly exceeds the variations which can be expected when a method is transferred from one instrument to another or from one laboratory to another.

\section{Application of proposed methods}

\section{Dissolution studies}

The selection of the dissolution medium was made by considering the solubility of vildagliptin in order to ensure sink conditions. As the drug in study is highly water soluble, in all conditions tested the sink conditions were achieved. The dissolution profiles were performed at three different dissolution media, within the physiological $\mathrm{pH}$ range (7). The sink conditions were determined in different solvents: $0.01 \mathrm{~mol} \mathrm{~L}^{-}$ $1 \mathrm{HCl}$, acetate buffer $\mathrm{pH} 4.5$ and 5.0 and phosphate buffer $\mathrm{pH}$ 6.0, 6.8 and 7.4. For dissolution tests, $900 \mathrm{~mL}$ of each medium were deaerated, by stirring and heating, and maintained at $37 \pm 0.5^{\circ} \mathrm{C}$. USP apparatus, paddle and basket, were tested. For paddle apparatus stirring speeds of 50 and $75 \mathrm{rpm}$ were tested and for basket 50 and $75 \mathrm{rpm}$ were tested. The test time was set on $60 \mathrm{~min}$. Aliquots of $5.0 \mathrm{~mL}$ were withdrawn from each vessel without replacement of dissolution medium. Later, calculations were performed for volume correction. The times selected were: $5 ; 10$; $15 ; 20 ; 30 ; 45$ and $60 \mathrm{~min}$. The samples were analyzed by derivative UV spectrophotometric method and HPLC method $(n=3)$.

\section{Results and discussion}

\section{Analytical Method Validation}

\section{D-UV method}

\section{Specificity}

Spectrophotometric methods are more economic and simple compared to methods such as chromatography and electrophoresis, and can provide a very useful alternative for quality control of pharmaceutical formulations. Derivative spectra can be used to clarify 
absorption bands in more complex UV spectra. In comparison with conventional spectrophotometric determinations, derivative spectrophotometry has proved to be of a great value in eliminating the interference from excipients and co-formulated drugs (13-16).

In order to evaluate specificity of the 2DUV method, placebo solutions were prepared and analyzed by zero-order UV spectrum showing strong and significant interference from the tablet excipients in all the region of VLG absorption spectrum, which prevent the analytical use of zero-order spectrophotometry (Figure 2a). The first derivative was also discarded due to lack of selectivity (Figure 2b). For this reason, the 2D-UV method was considered to be ideal for solving the overlapping of excipients absorption over VLG signal. As observed in Figure 2c, the zero-crossing for placebo solution appears at $220 \mathrm{~nm}$, using a $\Delta \lambda$ of $8 \mathrm{~nm}$ and 20 as scaling factor. Therefore, this value was selected as optimum to determine VLG in the presence of the pharmaceutical excipients.
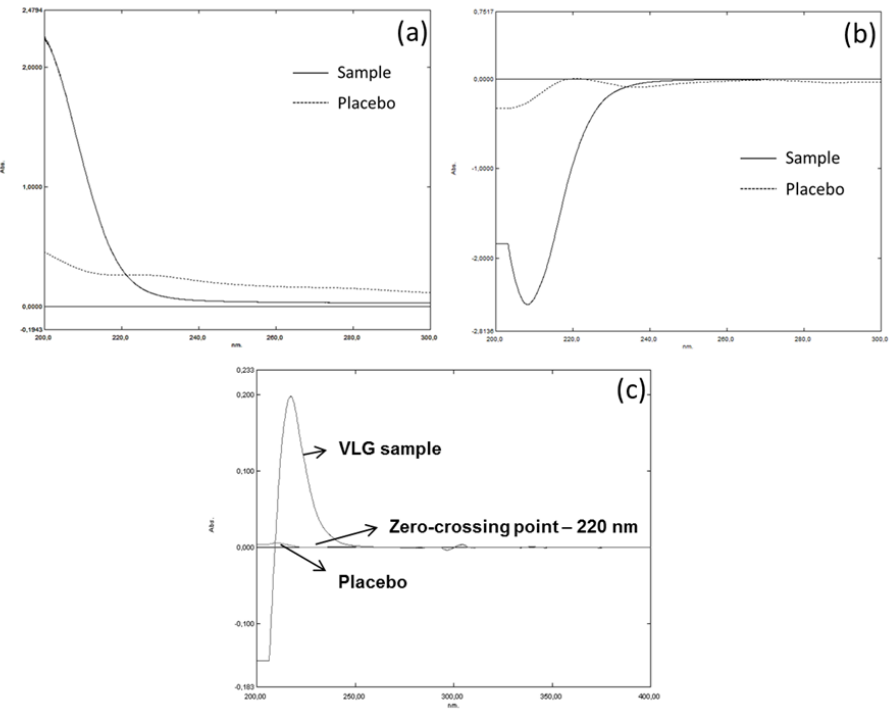

Figure 2. Zero-order absorption spectra (a), first-order derivative spectra (b) and second-order derivative spectra (c) of vildagliptin sample solution and placebo solution, in water at concentration of $100 \mu \mathrm{gL}^{-1}$.

\section{Linearity}

Linearity was observed over the concentration range of 25 to $175 \mu \mathrm{g} \mathrm{mL}^{-1}$ in 220 $\mathrm{nm}$ with linearity equation $\mathrm{y}=0.0015 \mathrm{x}+0.0033$ $\left(r^{2}=0.9995\right)$, where $x$ is the VLG concentration (expressed as $\mu \mathrm{g} \mathrm{mL} L^{-1}$ ) and $\mathrm{y}$ is the amplitude from the peak at $220 \mathrm{~nm}$. The variance analysis ( $\mathrm{p}$ $=0.05)$ was applied to verify the linearity of the method and the results showed that the regression equation was linear (Fcalculated $=60506.3$ > Fcritical $=4.60$ ) with no deviation from linearity $($ Fcalculated $=2.93<$ Fcritical $=2.96)$.

\section{Precision}

The experimental values obtained for the determination of the precision of analytical method are presented in Table 1 . The low relative standard deviation (RSD) obtained for the repeatability and intermediary precision showed the precision of the method.

Table 1. Inter-day and intraday precision data for vildagliptin in samples of pharmaceutical formulation obtained by UV derivative method at $220 \mathrm{~nm}$.

\begin{tabular}{|c|c|c|c|c|}
\hline \multirow{2}{*}{ Sample (n) } & \multicolumn{3}{|c|}{ Repeatability } & \multirow[t]{2}{*}{ Intermediate precision } \\
\hline & Day 1 & Day 2 & Day 3* & \\
\hline 1 & 97.97 & 99.86 & 97.78 & \\
\hline 2 & 99.47 & 97.16 & 97.78 & \\
\hline 3 & 97.78 & 97.99 & 96.51 & \\
\hline 4 & 98.41 & 98.87 & 97.34 & \\
\hline 5 & 97.78 & 96.91 & 97.97 & \\
\hline 6 & 99.04 & 97.55 & 97.15 & \\
\hline Mean $(\%)$ & 98.41 & 98.06 & 97.42 & 97.96 \\
\hline RSD & 0.72 & 1.14 & 0.55 & 0.88 \\
\hline
\end{tabular}

\section{Accuracy}

The accuracy of the method ranged 96.16 to $98.95 \%(\mathrm{RSD}=1.45)$. The results are shown in Table 2. These values showed the accuracy of the purposed method.

Table 2. Results of method accuracy for 2D-UV method applied to vildagliptin (VLG) in pharmaceutical formulation.

\begin{tabular}{|c|c|c|c|c|c|}
\hline Drug & $\begin{array}{l}\text { Added Level } \\
\qquad\left(\mu \mathrm{g} \mathrm{mL}^{-1}\right)\end{array}$ & $\begin{array}{l}\text { Total Nominal } \\
\text { Concentration } \\
\quad\left(\mu \mathrm{g} \mathrm{mL}^{-1}\right)\end{array}$ & $\begin{array}{c}\text { Mean } \\
\text { Concentration } \\
\text { found }^{\mathrm{a}} \\
\left(\mu \mathrm{g} \mathrm{mL}^{-1}\right)\end{array}$ & $\begin{array}{c}\text { Accuracy } \\
(\%)\end{array}$ & $\begin{array}{r}\mathrm{RSD}^{\mathrm{b}} \\
(\%)\end{array}$ \\
\hline \multirow{3}{*}{ VLG } & $25(25 \%)$ & 125.0 & 120.34 & 96.27 & 1.31 \\
\hline & $50(50 \%)$ & 150.0 & 144.02 & 96.01 & 0.44 \\
\hline & $75(75 \%)$ & 175.0 & 167.72 & 95.84 & 0.22 \\
\hline
\end{tabular}

${ }^{a}$ Mean of three replicates

${ }^{\mathrm{b}} \mathrm{RSD}=$ relative standard deviation 


\section{Robustness}

The results of the robustness study are presented in Table 3. They are expressed in percentage of the drug in relation to the nominal dose, calculated using standard solution in the nominal condition of the method.

Table 3. Responses (percentage of VLG in the commercial tablets relative to its label claimed concentration) obtained, in each assay, in relation to the standard solutions after changes in factors investigated by robustness test.

\begin{tabular}{ccccc}
\hline Experiment & $\begin{array}{c}\text { Mechanically } \\
\text { shaken (min) }\end{array}$ & $\begin{array}{c}\text { Ultrasonic } \\
\text { bath (min) }\end{array}$ & $\begin{array}{c}\text { Wavelength } \\
(\mathbf{n m})\end{array}$ & $\begin{array}{c}\text { Percentage of } \\
\text { VLG (\%) }\end{array}$ \\
\hline $\mathbf{1}$ & 6 & 15 & 222 & 98.65 \\
\hline $\mathbf{2}$ & 6 & 6 & 218 & 98.88 \\
\hline $\mathbf{3}$ & 15 & 6 & 218 & 99.09 \\
\hline $\mathbf{4}$ & 15 & 15 & 218 & 96.69 \\
\hline $\mathbf{5}$ & 6 & 15 & 222 & 96.91 \\
\hline $\mathbf{6}$ & 15 & 6 & 222 & 97.69 \\
\hline $\mathbf{7}$ & 15 & 6 & 218 & 98.69 \\
\hline $\mathbf{8}$ & 6 & 15 & 222 & 97.91 \\
\hline
\end{tabular}

The effects of the factors in analysis, the error estimated starting from the dummy factors and the value of $t$ calculated are shown in Table 4. The analysis of the results from robustness study demonstrated that the factors did not present significant effect on the quantitation of VLG, indicating the robustness of the UV derivative spectrophotometric method.

Table 4. Experimental values of the effects and t-calculated of the factors analyzed in the robustness testing for validation of $2 \mathrm{D}-\mathrm{UV}$ method applied to vildagliptin (VLG) in pharmaceutical formulation.

\begin{tabular}{lcc}
\hline Factor & $\mid$ Effect $\mid$ & $\boldsymbol{t}$-calculated \\
\hline Mechanically shaken & $\mathbf{1 . 0 4}$ & $2.48^{\mathrm{a}}$ \\
\hline Shaken in ultrasonic bath & $\mathbf{0 . 2 7}$ & $0.64^{\mathrm{a}}$ \\
\hline Wavelength of the detector & $\mathbf{0 . 5 5}$ & $1.30^{\mathrm{a}}$ \\
\hline
\end{tabular}

${ }^{a}$ No statistical difference to $t(0.05 ; 2)$; experimental error $\mathrm{Ee}=0.420$.

\section{HPLC method}

HPLC method here employed was based in a previously published paper (17), in which a HPLC method for the quantitation of VLG in pharmaceutical tablets was developed and validated. According to $\mathrm{ICH}$, revalidation may be necessary in the circumstances that there are changes in the composition of the finished product and/or in the analytical procedure. Therefore, the original method suffered one modification in the mobile phase content because it was applied for a different purpose. In this study the main objective was to quantify VLG from tablets in a dissolution test. Hence, the method was revalidated to meet this new proposal.

\section{Specificity}

The specificity was confirmed as the formulation excipients of the pharmaceutical tablet product did not interfere in the method determination at $207 \mathrm{~nm}$ (Figure 3), allowing reliable results.

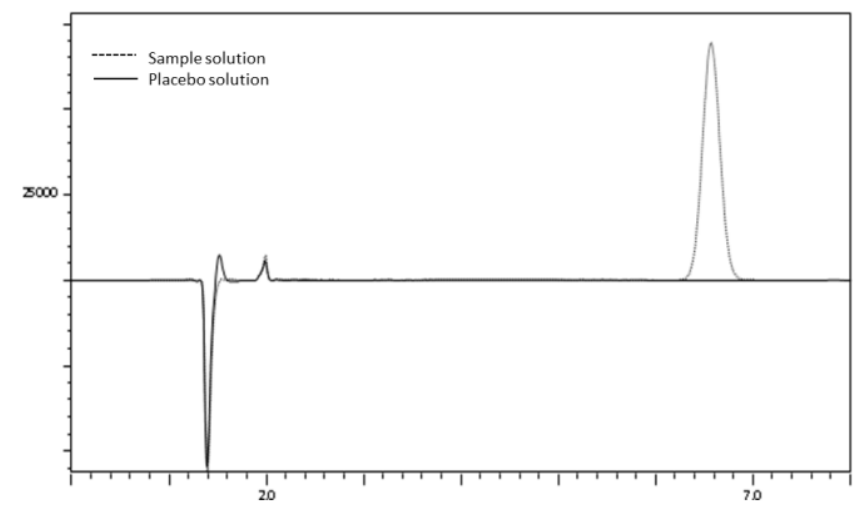

Figure 3. Vildagliptin sample solution chromatogram with placebo solution overlapping.

\section{Linearity}

Three analytical curves constructed for vildagliptin were found to be linear in the 10-90 $\mu \mathrm{g} \mathrm{mL}{ }^{-1}$ range. The value of the determination coefficient calculated $\left(\mathrm{r}^{2}=0.9999, \mathrm{y}=18354 \mathrm{x}\right.$ 3747.3) indicated the linearity of the analytical method. The validity of the assay was also verified by means of ANOVA, which demonstrated significant linear regression $(\mathrm{p}<$ $0.05)$ and non-significant linearity deviation ( $p>$ $0.05)$.

\section{Precision}

Repeatability and intermediate precision were determined and the obtained results are illustrated in Table 5. All the data are within the acceptance criteria (RSD) of $2 \%$, which indicate the method precision. 
Table 5. Results of intraday and interday precision for VLG tablets by HPLC method.

\begin{tabular}{lccc}
\hline & Day 1 (n=6) & Day 2 (n=6) & Day 3 (n=6) \\
\hline Average Intraday (\%) & 98.19 & 98.52 & 98.09 \\
\hline RSD Intraday $(\%)$ & 0.97 & 0.64 & 1.06 \\
\hline Average Interday $(\mathbf{n}=\mathbf{1 8})$ & & 98.27 & \\
\hline RSD Interday $(\%)$ & & 0.87 &
\end{tabular}

\section{Accuracy}

There were found excellent mean percentage recovery values. The mean recovery was $98.96 \%$ (RSD $=1.82 \%)$ for tablets. The results are presented in Table 6. At each level of VLG concentration, three determinations were performed.

Table 6. Experimental values obtained in the recovery test for vildagliptin by using HPLC method.

\begin{tabular}{|c|c|c|c|c|}
\hline $\begin{array}{c}\text { Added } \\
\text { level } \\
\left(\mu \mathrm{g} \mathrm{mL} \mathbf{L}^{-1}\right)\end{array}$ & $\begin{array}{c}\text { Nominal } \\
\text { concentration } \\
\left(\mu \mathrm{g} \mathrm{mL} \mathbf{~ L ~}^{-1}\right)\end{array}$ & 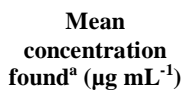 & $\begin{array}{c}\text { Accuracy } \\
(\%)\end{array}$ & RSD (\%) \\
\hline 10 & 40 & 49.87 & 99.74 & \\
\hline 20 & 40 & 58.98 & 98.30 & 0.89 \\
\hline 30 & 40 & 69.95 & 99.93 & \\
\hline
\end{tabular}

\section{Robustness}

Robustness was evaluated by small changes in the parameters like mobile phase composition and $\mathrm{pH}$, column temperature and flow rate. In robustness studies, it was observed that the column temperature did not affect the drug elution. However, the mobile phase composition and flow rate resulted in changes in drug retention time but these small changes did not affect drug determination in the pharmaceutical formulations.

\section{Dissolution performance validation}

Validation of dissolution performance was carried out by the two methods of quantification, 2D-UV and HPLC. The concentration of $50 \mathrm{mg}$ of vildagliptin in $900 \mathrm{~mL}$ of dissolution media is nearly equal to the central concentration $(55 \mu \mathrm{g}$ $\mathrm{mL}^{-1}$ ) at the established ranges.

Linearity was evaluated by three analytical curves of VLG standard in the dissolution media in range of $25-125 \mu \mathrm{g} \mathrm{mL}^{-1}$ (2D-UV method) and
10-90 $\mu \mathrm{g} \mathrm{mL} \mathrm{mL}^{-1}$ (HPLC method). The high correlation coefficients calculated demonstrate the linearity of the proposed methods (Table 7).

Table 7. Linearity results for dissolution studies of vildagliptin by 2D-UV and HPLC.

\begin{tabular}{lcc}
\hline Parameters & 2D-UV & HPLC \\
\hline Linearity range $\left(\mu \mathrm{g} \mathrm{mL}^{-1}\right)$ & $25-125$ & $10-90$ \\
\hline Slope & 0.0017 & 17884 \\
\hline Intercept & 0.0005 & 2115.3 \\
\hline Correlation coefficient $(\mathrm{r})$ & 1.000 & 0.9999 \\
\hline
\end{tabular}

Precision was determined by crushing twenty coated tablets, containing $50 \mathrm{mg}$ of drug, and checking their content by 2D-UV and HPLC instruments. Since this content is exactly known, the precision assay can be performed without the intrinsic variability of the tablets and dispensing the bulk and standard materials. The results for both validated methods were expressed as percentage of dissolution and RSD and are presented in Table 8 . The RSD values were less than $2.0 \%$ for repeatability and intermediate precision, indicating the precision of the dissolution method.

Table 8. Results of precision for dissolution test applied to vildagliptin tablets.

\begin{tabular}{ccccc}
\hline Samples & \multicolumn{2}{c}{ 2D-UV Assay $(\boldsymbol{\%})$} & \multicolumn{2}{c}{ HPLC Assay (\%) } \\
\hline & Day 1 & Day 2 & Day 1 & Day 2 \\
\hline 1 & 98.58 & 98.65 & 101.15 & 100.57 \\
\hline 2 & 99.39 & 98.02 & 99.35 & 100.28 \\
\hline 3 & 98.69 & 98.12 & 99.41 & 100.30 \\
\hline Mean & 98.89 & 98.26 & 99.97 & 100.38 \\
\hline RSD $(\boldsymbol{\%})$ & 0.44 & 0.35 & 1.02 & 0. \\
\hline
\end{tabular}

Mean/RSD Interday (\%): $98.58 / 0.50$

Mean/RSD Interday (\%): $100.18 / 0.69$

Accuracy of the method was demonstrated by the recovery of known amounts of VLG in the dissolution vessels. Three levels were evaluated (low, medium and high). The results obtained and the mean recoveries are described in Table 9, which represent the accuracy of the methods. 
Table 9. Recovery data for vildagliptin added to the dissolution vessels by using the proposed 2D-UV and HPLC methods.

\begin{tabular}{cccccc}
\hline Method & $\begin{array}{c}\text { Levels } \\
(\boldsymbol{\%})\end{array}$ & $\begin{array}{c}\text { Added VLG } \\
(\mathbf{m g})\end{array}$ & $\begin{array}{c}\text { Amount found } \\
(\mathbf{m g})\end{array}$ & $\begin{array}{c}\text { Recovery } \\
(\boldsymbol{\%})\end{array}$ & $\begin{array}{c}\text { RSD } \\
(\boldsymbol{\%})\end{array}$ \\
\hline 2D-UV & 25 & 12.50 & 12.30 & 98.42 & 0.26 \\
\hline & 100 & 50.00 & 49.49 & 98.98 & 0.72 \\
\hline & 125 & 62.50 & 61.96 & 99.13 & 0.10 \\
\hline HPLC & 25 & 12.50 & 12.36 & 98.88 & 0.30 \\
\hline & 100 & 50.00 & 49.46 & 98.92 & 0.75 \\
\hline & 125 & 62.50 & 62.22 & 99.55 & 0.33 \\
\hline
\end{tabular}

The drug release profile determined by the dissolution test conditions in Dissolution Studies Section (obtained for 2D-UV and HPLC method) is illustrated in Figure 4. The results are expressed as VLG concentration dissolved versus time. The obtained profiles were considered satisfactory once in conditions evaluated in another media by $\mathrm{pH}$ differences, apparatus and rotation speed the drug liberation occurred mainly in the first time points. The dissolution is quite fast, about $80 \%$ of the drug was dissolved within $10 \mathrm{~min}$ and the drug dissolution was concluded within $30 \mathrm{~min}$.

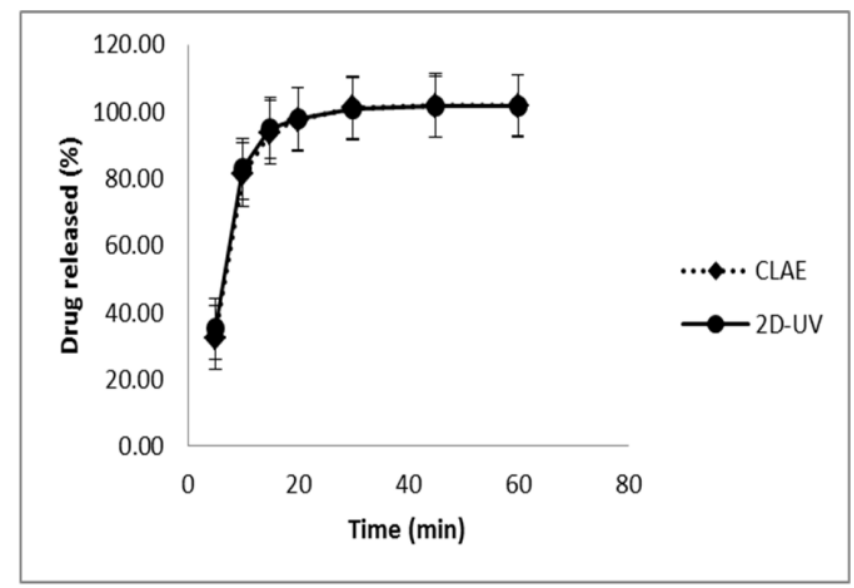

Figure 4. Dissolution profile of vildagliptin from tablets by CLAE and UV second derivative measurements.

\section{Comparation between $2 D-U V$ and HPLC methods} applied in dissolution test to vildagliptin in tablets

The validated 2D-UV spectrophotometric method was applied for the dissolution test of VLG in tablet dosage form and the results compared to those obtained using the HPLC method, as shown in Table 10. The experimental values of the two methods were compared statistically by ANOVA showing non-significant difference $(p>0.05)$.

Table 10. Comparative determination applied for the dissolution test of vildagliptin in tablet dosage forms by 2D-UV and HPLC methods at 30 minutes.

\begin{tabular}{lcccc}
\hline & $\begin{array}{c}\text { 2D-UV method } \\
\text { Experimental amount } \\
(\mathrm{mg} / \text { tablet })\end{array}$ & $\begin{array}{c}\text { RSD } \\
\mathbf{( \% )}\end{array}$ & $\begin{array}{c}\text { HPLC method } \\
\text { Experimental amount } \\
(\mathrm{mg} / \text { tablet })\end{array}$ & $\begin{array}{c}\text { RSD } \\
(\boldsymbol{\%})\end{array}$ \\
\hline Day 1* & 49.31 & 0.05 & 50.43 & 0.41 \\
\hline Day 2* & 49.35 & 0.98 & 49.91 & 0.66 \\
\hline Day 3* & 49.20 & 0.41 & 49.93 & 0.63 \\
\hline *Mean of six determinations & & &
\end{tabular}

\section{Conclusions}

A dissolution test for vildagliptin tablets determination was presented in this study. 2D-UV and HPLC analytical methods were validated and can be used to quantitation and evaluation of the release profile of vildagliptin in tablets. There is no significant difference between the validated HPLC and 2D-UV methods. It represents that both methods are useful for quantitative determination and dissolution evaluation of vildagliptin and can be applied in the laboratory routine analysis.

\section{Acknowledgments}

The authors wish to thank CAPES and $\mathrm{CNPq} /$ Brazil for the financial support.

\section{Conflict of interest}

The authors declare no conflict of interest.

\section{References}

1. Mathieu, C; Diabetes, Obesity and Metabolism, 2009, 11(2): 9-17.

2. Srinivasan, B.T., Jarvis, J., Khunti, K. and Davies, M.J.; Postgraduate Medical Journal, 2008, 84: 524-531.

3. Kahn, S.E., Haffner, S.M., Heise, M.A., Herman, W.H., Holman, R.R. and Jones, 
N.P.; New England Journal of Medicine, 2006, 355: 2427-2443.

4. Del, P.S., Bianchi, C. and Marchetti, P.; Diabetes \& Metabolism, 2007, 23; 518-527.

5. Bolli, G., Dotta, F., Colin, L., Minic, B. And Goodman, M.; Diabetes, Obesity and Metabolism, 2009, 11: 589-595.

6. Kamberi, M. and Tran, T.; Journal of Pharmaceutical and Biomedical Analysis, 2012, 70: 94-100.

7. Food and Drug Administration; Guidance for industry: immediate release solid oral dosage forms: scale-up and post-approval changes, U. S. Department of Health and Human Services, Center for Drug Evaluation and Research, Rockville, USA, 1995.

8. Rozet, E., Ziemonsa, E., Marinia, R.D., Boulanger, B. and Hubert, P.; Analytica Chimica Acta, 2012, 751: 44-51.

9. Tomsu, D., Catalá Icardo, M. and Martínez Calatayud, J.; Journal of Pharmaceutical and Biomedical Analysis, 2004, 36: 549557.

10. Gorog, S.; Analytical Sciences, 2004, 20(5): 767-782.

11. Karpinska, J.; Talanta, 2004, 64: 801-822.
12. El-Sayed, A.Y. and El-Salem, N.A.; Analytical Sciences, 2005, 21(6): 595-614.

13. Rojas, F. and Ojeda, C.; Analytica Chimica Acta, 2009, 635: 22-44.

14. The United States Pharmacopoeia, USP 39, United States Pharmacopeial Convention, Rockville, USA, 2016.

15. International Conference on Harmonization; ICH Guideline Q2(R1): Validation of Analytical Procedures: Text and Methodology, Geneva, Switzerland, 2005.

16. Sznitowska, M. and Stokrocka, M.; Acta Poloniae Pharmaceutica-Drug Research, 2007, 63(5): 401-405.

17. Barden, A.T., Salamon, B., Schapoval, E.E.S. and Steppe, M.; Journal of Chromatographic Science, 2012, 50: 426432. 